\title{
NATIONAL SMART CITIES STRATEGY AND ACTION PLAN: THE TURKEY'S SMART CITIES APPROACH
}

\author{
D. Y. Bayar ${ }^{1}$, H. Guven ${ }^{1}$, H. Badem ${ }^{1 *}$, E. Soylu Sengor ${ }^{1}$ \\ ${ }^{1}$ The Ministry of Environment and Urbanization, 06530 Çankaya Ankara, Turkey - (dyildirim.bayar, hakan.guven, harun.badem, \\ eda.soylu)@csb.gov.tr
}

KEY WORDS: Smart City, National Strategy, Action Plan, Smart City Components, Smart City Approach, Sustainable Cities, Livable Cities

\begin{abstract}
:
Nowadays, cities need sustainable approaches that take care of the future in order to meet the needs that arise with population activity. Accordingly, for making cities more livable, the necessity of ensuring efficient use of urban sources and planning urban infrastructures brings the smart city concept into the forefront. The smart city solutions are frequently applied by many local governments and stakeholders. For this reason, there is a need to support the collaboration of all relevant actors and to provide a common national strategic perspective among smart city stakeholders. In the Strategic Plan of the Ministry of Environment and Urbanization, the objectives of smart cities and national geographic information services are determined as "to make infrastructure works in order to establish smart cities, to improve the spatial management in cities with the help of technology, to share data to improve public services and to be the focus of national geographical information" and studies on these objectives have been completed. Accordingly, the "2020-2023 National Smart Cities Strategy and Action Plan" has been prepared in order to establish a national strategic view on smart cities and draw a road map under the policy ownership of the Ministry of Environment and Urbanization. By the implementation of this strategy and action plan with the vision of "Livable and Sustainable Cities that Add Value to Life", a new process of transformation and change will be provided to cities that take care of the real needs of citizens, adopting participatory governance by using resources effectively.
\end{abstract}

\section{INTRODUCTION}

\subsection{General Instructions}

The technological advancements and innovative approaches, with their ever-growing number and quality, has a powerful transformative effect on the urban life. Named as Smart City, this transformation aims at enabling the city to manage itself through futuristic projections based on data and expertise without the need of human intervention by means of establishing powerful networks between the assets living in the city and ensuring the interoperability with the collaboration of the whole ecosystem stakeholders. Smart City provides sustainable development, competitive power, along with the acquirements in environmental sustainability thanks to its ability to turn the information it provides into economic, social and environmental advantages. With a similar motivation in our country, 2020-2023 National Smart Cities Strategy and Action Plan has been drawn up with the aim to gain the ability of interoperability by means of bringing an integrated perspective into Smart City policies at national level, and to ensure that the investments are utilized in the correct projects and activities by the competent and producing Smart City Ecosystem by means of prioritizing the investments that meet the requirements of the designated policies. With an integrated strategy address the needs of the stakeholders, paying regard to the current state by attaching importance to the experiences gained, and evaluating the international applications, it is aimed

1. To set a mutual vision and a roadmap,

2. To monitor and evaluate with a systematic and open governance process,

3. To adapt to changing new conditions,
4. To develop Smart City maturity with a common perspective in the cities.

2020-2023 National Smart Cities Strategy and Action Plan is the first Smart City strategy and action plan, and the fourth in the World, drawn up at national level, and which is shaped with a common sense and scientific perspective by participation of the central government institutions and organizations, local governments, private sector, nongovernmental organizations and universities. National policy documents and legislative frameworks were examined, international literature researches were realised, workshops and meetings were held covering all stakeholders and large-scale surveys were conducted to local governments. While establishing the 2020-2023 National Smart City Strategy, the requirements and best applications within the scope of Smart City maturity models, along with the applications from other countries, international developments, technological innovations and trends have been taken into consideration in line with the opportunities, conditions, needs and priorities that are specific to Turkey. 2020-2023 National Smart Cities Strategy and Action Plan will give acceleration to the social, economic and environmental development of Turkey by addressing Smart City transformation needs. By focusing on "Effective and Sustainable Smart City Governance" and "Competent and Producing Smart City Ecosystem", this strategy established its vision as "Livable and Sustainable Cities that Add Value to Life". In line with this vision, 4 strategic goals, 9 objectives and 40 actions have been determined. For successful implementation of 2020-2023 National Smart Cities Strategy and Action Plan, active participation of whole ecosystem stakeholders are needed.

\footnotetext{
* Corresponding author
} 


\section{WHAT IS SMART CITY?}

The need to ensure cities sustainably, countries and cities are applying to new technologies and innovative approaches. For meeting this need, Smart City approach comes as a solution. More clearly, what is aimed with Smart City is:

1. To convert the existing and future expectations \& problems of the city into a triggering power in all the spaces and systems of the city,

2. To approach the physical, social and digital planning all together,

3. To predict, identify and overcome the emerging challenges,

4. To reveal the integrated service delivery and the potential for generating innovations by means of ensuring the interaction between the enterprise agencies in the city.

Smart City does not describe a static approach to the future of cities. But rather, it tackles the innovative use of technology and data, along with enterprise change, which has the ability to guide the delivery of different dynamic city visions under more effective, productive and sustainable ways for future cities. In other words, it is aimed to transform the traditional governance method followed by cities. The traditional governance model of a city is based on functionally oriented service providers that generally work as vertical silos that are not built around user needs and do not work in collaboration. Smart Cities need to develop new operating models that promote innovation and collaboration among these vertical silos. In this case, the residents and the business world are obliged to communicate with each silo separately instead of receiving an uninterrupted and connected service that meets their needs. However, data and expertise remain within these silos, limiting the potential for collaboration and innovation within the city general and the potential for data and expertise to increase the city's pace of change. Smart City has come to the forefront as an approach that evaluates this potential and gained importance not only in our country, but also across the world. Efforts in the Smart City field have gained momentum to create better living spaces, as well as building cities that add value to life.

Describing the term "Smart City" is the primary step in terms of addressing Smart City studies. In the preparatory studies for 2020-2023 National Smart Cities Strategy and Action Plan, the definitions of Smart City that are within various studies as oriented to this need have been reviewed:

1. Smart City provides the effective integration of physical, digital and human systems to provide a sustainable, prosperous and inclusive future to Ecosystem assets (BSI, 2014).

2. Smart Cities are defined as a process that makes cities more livable, flexible and more responsive to challenges by encouraging citizenship participation rather than a static result, as well as improving the physical infrastructure (BIS, 2013).

3. Smart City is a city that adopts an approach to solve public problems with ICT based solutions based on multi-stakeholder, municipalityoriented stakeholdership (Directorate-General for Internal Policies of European Parliament, 2014).

4. Smart City is a combination of all available information and a better understanding of the city's activities, control and efficient use of limited resources (Cosgrove $\mathrm{M}$ and al, 2011)

5. Smart City is defined as a smart citizen where citizens have all the information they need to make informed choices about their lifestyle, business and travel options (MDDA, 2019).

6. Smart City is a tool that can constantly follow new developments to create a livable and sustainable environment for everyone (City of Copenhagen Definition, 2019).

7. Smart and sustainable city, while considering the economic, social, environmental and cultural needs of current and future generations on one side, it is also recognized as an innovative city that uses information and communication technologies and other tools to increase the quality of life, efficiency and competitiveness of city service provision (ITU, 2016).

It has been understood that there is no common definition of the term "Smart City", and that this definition is formed according to the needs for which the required solutions are sought. Within the scope of 2020-2023 National Smart Cities Strategy and Action Plan, the term "Smart City" has been described as follows: "More livable and sustainable cities that are brought into being with the inter-stakeholder collaboration, utilizing emerging technologies and innovative approaches, providing justification based on data and specialty, and producing solutions adding value to our lives by predicting the future problems and needs" (General Directorate of Geographical Information Systems, 2019). As a complex concept, the term "Smart City" needs to be addressed structurally. Not only are there various definitions of this term, there are also various approaches within the scope of standard, maturity assessment model, index and architecture studies concerning the conceptual structure of Smart City. Among these approaches are there 6 main components in the structure used by the European Parliament (Directorate-General for Internal Policies of European Parliament, 2014). These Components are: Smart Economy, Smart Residents, Smart Governance, Smart Living, Smart Mobility and Smart Environment.

Smart City Components within the scope of PAS 181 Smart City Framework (BSI, 2014) are "Energy, Waste, Water, Communication, Security and Emergency, Education and Training, Transportation, Health, Social Services, Housing, Environment, Finance and Economy". ISO 37120: 2014 Sustainable Development of Communities - Indicators for City Services and Quality of Life (BSI, 2014) under 17 Smart Components include certain indicators, which are as follows: Economy, Education, Energy, Environment, Finance, Fire and Emergency Response, Governance, Health, Recreation, Security, Housing, Solid Waste, Telecommunications and Innovation, Transportation, City Planning, Waste Water and Water Reuse.

The components identified under the ITU - Shaping Smarter and More Sustainable Cities (ITU, 2016) are "Information and Communication Technologies (ICT), Environmental Sustainability, Efficiency, Quality of Life, Equality and Social Inclusion and Physical Infrastructure". Within the scope of UNECE / ITU Smart Sustainable Cities Indicators (UNECE, 2015), 18 Development Areas are defined under 3 main components: "ICT Infrastructure, Innovation, Employment, Trade (sub-headings: e-Commerce and import / export), Efficiency, Physical Infrastructure subheadings: water 
transported in pipes, health, electricity, transportation and structures). Within the scope of the environmental component, Air Quality, Water, Noise, Environmental Quality, Biodiversity and Energy development areas are defined. Within the scope of Community and Culture component, Education, Health, Security (subheadings: disasters, emergency and ICT), Housing, Culture, Social Inclusion development areas were determined.

The components within Smart Cities Readiness Guide developed by Smart Cities Council are Built Environment, Energy, Telecommunication, Transportation, Health and Social Services, Water and Wastewater, Waste Management, Public Safety, Finance and Payments. Within the scope of Smart Cities Ranking Model (Centre of Regional Science, 2007) for European Union European Medium-sized Cities, six components have been identified: Smart Economy, Smart People, Smart Management, Smart Mobility, Smart Environment and Smart living.

These various approaches concerning the structure of Smart City have been reviewed, and Smart City Structure has been addressed under two main headings within the scope of 20202023 National Smart Cities Strategy and Action Plan, which are "Smart City Management" and "Smart City Applications".

The competences of Smart City Management and Smart City Applications included in Smart City Structure, along with the Smart City Components are in the Figure 1.

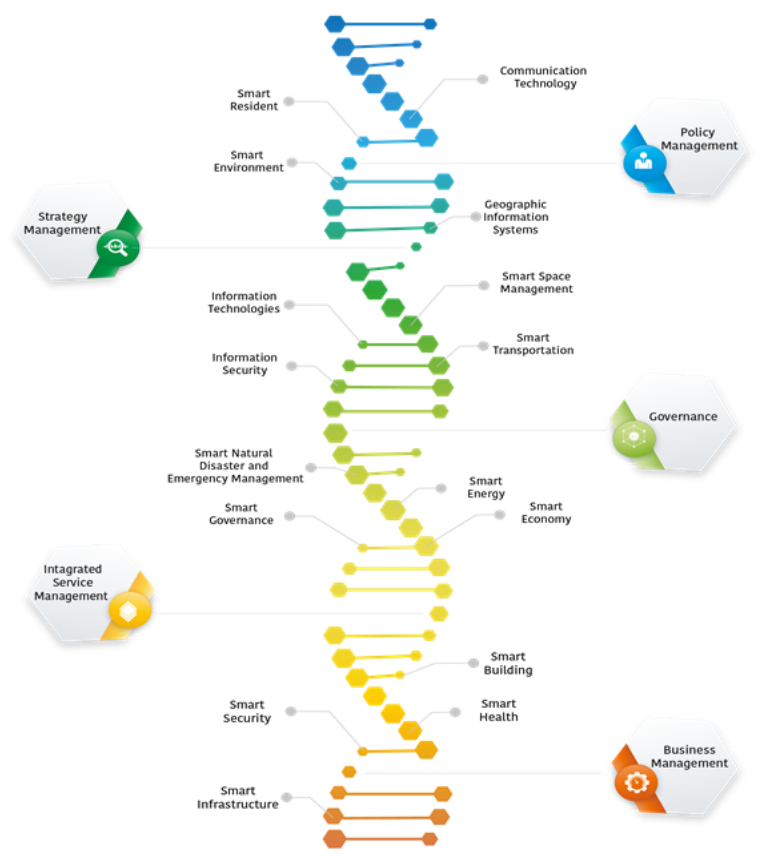

Figure 1. 2020-2023 National Smart Cities Strategy and Action Plan Smart City Structure

\section{GENERAL VIEW OF SMART CITY}

\subsection{Across The World}

Smart City works \& studies are carried out in many countries in line with the strategies prepared on the basis of cities. New York, Seoul, Barcelona, Berlin, London, Manchester, Toronto, Sau Paulo, Dublin, Chicago are some of the important cities having smart city strategy.
The Smart City approach has a structure that has changed over the years due to its nature. In this respect, the motivations of Smart City strategies have also changed over the years. The Smart City strategies developed by the cities are gathered around three main motivations in general, which are as follows:

1. Economic Motivations: The use of technology to improve services and increase productivity, and to invest and increase economic development.

2. Social Motivations: Encouraging the citizens inclusiveness, trust, empowerment and transparency.

3. Environmental Motivations: The works \& studies to ensure environmental sustainability

The first examples of Smart City studies focused on the benefits of using technologies to achieve efficiency. As the term "Smart City" is moving towards a citizen-centered vision, the focus of the strategies has shifted towards the objectives of increasing citizens' participation and improving the quality of life. While the economy was the focal point of the strategies before 2013, the main motivation of the strategies after 2013 became social and environmental issues.

In general, smart city strategies are developed through two different approaches. These are the Collaborative Approach and the Top-Down Approach. The Collaborative Approach generally involves a broader stakeholder engagement process through the establishment of a public Smart City network or working group. The Smart City strategies in Europe, North and South America, Africa and Australia have been developed through a collaborative process. In Toronto, a Smart Cities Working Group was constituted to determine what a smarter concept might mean when developing a Smart City strategy. The city has worked closely with its stakeholders. Similarly, Dublin has established a business-oriented Advisory Network to advise on the creation of the Smart Dublin Strategy. Both cities started by gathering information about what was happening in the city to provide input to the strategy. The Top-Down Approach to strategy building is an internal process that focuses on the involvement of relevant city departments. In general manner, Asian cities have a special purpose committee or government agency responsible for strategy implementation and direction. In Seoul, for example, the strategy development phase was led by the Information Office in collaboration with the relevant departments. The Digital Strategy Committee consists of IT experts, city planners and Academicians.

National Smart City strategies have been developed by the Netherlands, Austria, Hong Kong and the USA to provide common understanding and coordination whole the country as well as the strategies prepared by the cities.

The focus of Smart Cities around the world varies from country to country in general. In European countries, efforts to reduce carbon emissions, attract and protect the young population, support the aging population, reduce costs to cover budget deficits and broadband infrastructure come to the forefront.

The creation of new business opportunities in the United States, revitalizing economic conditions, reducing costs to close budget deficits, creating product options for the economic and social benefits of city digitalization, coping with the increasing city population, supporting transparency in management and improving ICT infrastructure stand out in this process. In Asian countries, optimizing consumption, providing better public services, branding cities, resolving the shortage of funds in the 
Middle East and Africa, developing new industries and creating new business areas come to the forefront, as well.

Examining the city models prominent in the world, it can be seen that two different implementation methods are adopted. While some cities are built from the bottom up to be a pioneer in technology or a center of attraction in terms of technology, others prefer the way to update and improve their existing infrastructure. Some of examples are given below:

1. India launched an urban modernization initiative called "The Smart Cities Mission" in 2015 with the objective of establishing 100 Smart Cities in five years, and the National government allocated 480 billion rupees (US $\$ 7.5$ billion) for this initiative. Certain cities participating in the processes within this scope focus on the use of information and communication technology. Majority of the Smart Cities Mission has focused on basic modernization and quality of life in cities such as providing reliable electricity, water supply and waste management. The Ministry of Housing and Urban Affairs, which manages the Smart Cities Mission, has acted delicately in order not to emphasize the use of data and Smart Technology in the definition of Smart Cities. In this respect, it can be seen that India's Smart Cities Mission differs from the generally accepted Smart City definition.

2. Singapore has an advantageous position in developing Smart City technology as it is a city-state. Within the scope of Smart City activities in Singapore, an investment of $\$ 1.6$ billion was made in 2014 for the development, deployment and support of a national sensor network system and the Smart Nation Initiative. An investment of $\$ 2.8$ billion has also been made in the Smart Nation Initiative to extend nationwide Wi-Fi coverage to every public school, to optimize and increase the state's storage capacity, and to provide laptops to all government officials within three to five years. Singapore's Smart City technology covers all areas of the city, from green energy initiatives in residential to the development of an autonomous bus system throughout the city. Another important initiative of Singapore in the Field of smart city is the "Virtual Singapore". Virtual Singapore is a digital three-dimensional model of the island that serves as a dashboard for municipal data sources, including census information and geographic information systems. In addition, Virtual Singapore includes a wide range of useful urban planning and management applications, such as interactive simulations that show how new buildings will affect airflow in the city or how changing bus routes will affect travel times throughout Singapore.

3. South Korea did the honors for Songdo City - the Smart City built to create the world's first private economic zone. Sensors placed on roads, buildings and public transport, as well as the Internet of objects technologies cover the entire city.

4. In 2012, within the scope of Smart City works\&studies in the UK, Innovate UK as the UK's innovation agency has assigned 34.5 million pounds (US \$ 55.89 million) for 30 cities including Glasgow, Bristol and London to explore and develop Smart City policies on how Smart City technology can provide benefit to cities. In 2013, Innovate UK launched Future Cities Catapult, an urban innovation center with economists, engineers, operators and city authorities to finance and build Smart City applications. In 2015, Innovate UK raised $£ 10$ million (\$ $\$ 16.2$ million) to create a pilot zone in Manchester for the demonstration of CityVerve Smart City applications.

5. United States Smart City works\&studies were initiated by the Federal Government in 2015 with the Smart Cities Initiative. \$ 160 million was raised to a wide range of Internet applications of objects, including Smart Cities. In addition, the Smart Cities Initiative supports various programs, such as the National City of Standards and Technology Institute's Global City Teams Competition, which encourages the development of Smart City applications and the establishment of a test environment for vehicle pilots and objects connected to the Internet. In addition to all these efforts, the Federal Government's Network and Information Technology Research and Development Program has published the Smart Cities and Communities Framework, a guide for coordinating the Federal Agency within the scope of Smart City technology investments and collaboration.

\subsection{In Turkey}

The first policy on Smart Cities in Turkey is for the Smart Transportation component, as one of the Smart City Components, and is included in the National Science and Technology Policies 2003-2023 Strategy Document. Within the scope of the policy of "Gaining the Ability to Develop Contemporary and Safe Transportation Systems" in line with the aim of "Improving the Quality of Life" in the document, actions to develop smart vehicles and smart road systems for road transportation and to develop fire and security systems for transportation and tourism superstructures have been determined, as well.

In 2009, "increasing the spatial life quality of the urban settlements, empowering the economic and social structure, and restructuring of spatial planning system" has been defined as the increasing needs of cities within the scope of 2010-2012 Medium Term Program", and based on this need the "Urban Development Strategy and Action Plan" has been projected to be prepared. In the 9th Development Plan for the year 2010, "Improving the Life Qualities of Cities and Ensuring Sustainable Development" has been identified to be the prioritized policy, thus aiming at drawing up of the "Sustainable Urban Development and Action Plan". In line with all these policies "2010-2023 KENTGES Integrative Urban Development Strategy and Action Plan" has been drawn up. KENTGES, which is a strategy and a reference document at national level, is among the strategies and policies to be considered in the field of Smart City, based on an understanding that adopts the values system and principles related to urbanization, settlement and spatial planning.

The first holistic high-level policy in the field of Smart Cities is set out in the 10th Development Plan (2014-2018). Within the plan for the Smart Cities, the following policies are included:

1. "656. Urbanization and urban transformation will be handled in an integrated manner with manufacturing industry. Within this framework, production and export capacity will be increased in areas such as 
smart buildings, building materials, public transportation vehicles and signalling systems."

2. "The use of smart applications numbered as 731 for Livable Spaces, Sustainable Environment will be expanded especially in areas such as health, transportation, building, energy and disaster and water management. The transformation of cities into smart cities will be supported by increasing their infrastructure, capacity and skill levels in the field of information and communication technologies."

3. "Developing collaboration, coordination and data exchange among relevant organizations and enhancing the role of private sector, local governments and non-governmental organizations in the implementation, monitoring and assessment of policies in this field are of importance in order to take it to the next level in line with the sustainable development approach no. 900 determined for Livable Spaces and Sustainable Environment gain more and more importance."

4. "Applications encouraging eco-friendly production through innovative and value-added sectors, creative industries and state-of-the-art technology will be prioritized within the scope of urban transformation Project no.: 864 for "Livable Spaces and Sustainable Environment".

5. The information technologies and smart transportation systems will be effectively utilized for traffic management in urban transportation and public transportation services will be effectively utilized in line with the principle no.: 987 for "Urban Infrastructure".

The policies and actions related to Smart City and Smart City Components are included in the Prioritized Transformation Programs drafted within the scope of 10th Development Plan, as well:

1. The following actions were defined for "Improving Energy Efficiency in Transportation" as the 5th Component within the scope of 1.14. Energy Efficiency Improvement Program: "5.1: Expanding public transportation, small engine volume, electric and hybrid vehicle use in transportation, establishing smart bicycle networks in suitable settlements and creating pedestrian roads" and "Action 24: Highly Energy-efficient and climate sensitive urban transport strategies will be drawn up and implemented", and "Action 27: Smart Signalization Systems will be expanded.".

2. The following actions were defined for "Improving Local Capacity, Governance and Participation" as the 2nd Component within the scope of 1.23. Local Corporate Capacity Improvement Program: "2.2: Improving the technological infrastructure of institutions in the local layer, especially local governments, increasing the speed and quality of services", "Action 24: Feasibility studies of metropolitan municipalities for smart city applications will be supported."

3. The following policy was defined for "Encouraging the Domestic and Innovative Production in Urban Transformation" as the 2nd Component within the scope of 1.24. Urban Transformation Program for Improving Competitiveness and Social Cohesion": "Promoting the domestic development and production of advanced materials, Smart building technologies, application tools that improve durability and high technical construction machines.

The policy "101-Emphasis will be placed on supporting the sectors that create added value in urban transformation, creative industries, high-tech, environmentally friendly innovative production and energy efficiency." was defined related to the cities in 2015-2017 Medium-Term Program. Then, the policy "110. Importance will be given to supporting the sectors that create added value in urbanization and urban transformation, creative industries, high technology, environmentally friendly innovative production and energy efficiency." was defined in 2016-2018 Medium Term Program. Similarly, the policy "76. The transformation into an open, competitive, innovative, high value added, R \& D based and environmentally sensitive production structure led by the private sector will be accelerated. For this, a high-quality employment infrastructure will be established, the entrepreneurship capacity will be strengthened, the functioning of commercialization and branding processes will be increased, and health industries will be supported to create added value in urbanization and urban transformation." was included in the 2017-2019 Medium Term Program. The policies "Urban transformation will be evaluated in the direction of producing innovative products for the domestic manufacturing industry." and "The transition to smart applications supported by information and communication technologies (such as smart transportation systems, buildings, urban and energy infrastructures) will be accelerated." were defined in 2018-2020 Medium Term Program.

The Smart Cities Strategy and Feasibility Study Project was included in the 2015 Investment Program as the policies regarding Smart Cities and cities started to be included in the high level policy documents. The project owner is defined as the Ministry of Environment and Urbanization. Turkey's 2023 environment and urbanization vision of the Project in support of Environment and Urban Development Ministry's 2015-2017 Strategic Plan is indicated as follows: Our vision is to become a country that protects and maintains its rich, natural, historical, cultural and human resources, while on the other hand integrating with innovation and technology, having a competitive power, reducing the difference in development within and between regions, and having an improved quality of life. In addition, in line with this vision, information technology and spatial data infrastructure issues are mentioned among the duties, authorities and responsibilities of the Ministry of Environment and Urbanization. In the 2019-2023 Strategic Plan of the Ministry, this task is included as Smart Cities and National Geographic Information Services within the fourth aim.

With the triggering of the 10th Development Plan, many sectoral and thematic strategies and policies regarding Smart City and Smart City Components were included in the strategic plan of the institution. 2015-2018 Information Society Strategy and Action Plan, 2016-2019 National e-Government Strategy and Action Plan, 2010-2023 KENTGES Integrated Urban Development Strategy and Action Plan, 2016-2019 National Cyber Security Strategy and Action Plan, 2017-2023 National Energy Efficiency Action Plan and National Smart Transport Systems Strategy Document and Action Plan can be cited as examples of sectoral and thematic strategies for Smart Cities.

The policies developed in the Smart City with the 11th Development Plan (2019-2023), published in July 2019, were approached with in a holistic and prioritized manner with 
reference to the National Smart Cities Strategy and Action Plan and defined its vision as "99. National Strategy and Action Plan prepared by the Smart Cities in Turkey is guided by the objective of becoming the local management of Smart Cities.", and the related policies and measures are as follows:

1. 683. Local governments will be encouraged to establish smart city strategies and road maps to be followed, selection and implementation of smart city projects taking into account the prioritized areas and capabilities at the national level will be ensured, and domestic production for Smart City applications will be supported.

2. 683.1. Guidance will be provided to local governments on the basis of the National Smart City Strategy and Action Plan to establish smart city strategies and road maps to follow.

3. 683.2. Smart city projects will be prioritized by considering smart city maturity assessment and resource allocation constraints, primarily metropolitan municipalities and 51 provincial municipalities.

4. 683.3. The methods of supporting domestic technology applications within the scope of Smart City will be analysed and the respective criteria will be determined, primarily the domestic production rate to be taken as basis in the tender processes.

5. 683.4. By analysing the Smart City ecosystem, all stakeholders of the sector such as entrepreneurs, system developers and technology providers will be brought together on a digital platform.

There are many policies and measures in the new economic programs to support the policies of the 11th Development Plan. The policies "Turkey's National Geographic Information System infrastructure will be established and the transition to the Smart Cities will be prepared." as mentioned in the New Economy Program (Medium Term Program) 2019-2021, and "In line with the National Smart Cities Strategy and Action Plan, the competitive environment, technology infrastructure and effective data security necessary for the development of domestic and national technologies in this field will be enabled by establishing the Smart City ecosystem in our country within a healthy, comprehensive and sustainable manner." as mentioned in the New Economy Program (Medium Term Program 2020-2022) directly indicate the basis of Smart Cities.

\section{TURKEY'S PRIOR ACTIONS FOR SMART CITIES}

In Turkey, smart city studies are carried out in order to improve the quality of life of our citizens, to meet their urban needs, and to ensure the sustainability of environment. Today, numerous successful smart city applications and technologies are tried to be implemented by municipalities in our country. Mostly, the studies are realised repeatedly and for many projects it is hard to ensure sustainable and efficient coordination. In order to achieve modern smart cities in Turkey, it is essential to act within the framework of a common strategy and action plan in cooperation with all smart city stakeholders in Turkey. The 2020-2023 National Smart Cities Strategy and Action Plan has been prepared by the Ministry of Environment and Urbanization in cooperation with central government institutions and organizations, municipalities, private sector and nongovernmental organizations and universities. During the preparation of the Strategy and Action Plan, requirements and best practices and other country practices, international developments, technological innovations and trends are taken into account in line with Turkey's unique and specific conditions.

Within the scope of the 2020-2023 National Smart Cities Strategy and Action Plan, 65 national strategy documents, 6 international strategy documents, 4 country approach, 3 country strategy and 133 national legislation documents were examined. On the other hand, surveys were conducted to determine the needs of municipalities with the participation of 327 local governments and to identify current situation analysis for smart city visions and actions. The information of the needs of smart city strategy management, organization, investment and financial resources, data management, communication infrastructure and information security, smart city applications, best practises and the data were gathered in smart city survey works. In the 2020-2023 National Smart Cities Strategy and Action Plan, 4 Strategic Aims, 9 Targets and 40 Actions are specified and the maturity evaluation model, the monitoring and evaluation model and monitoring evaluation system was prepared and developed (Figure 2).

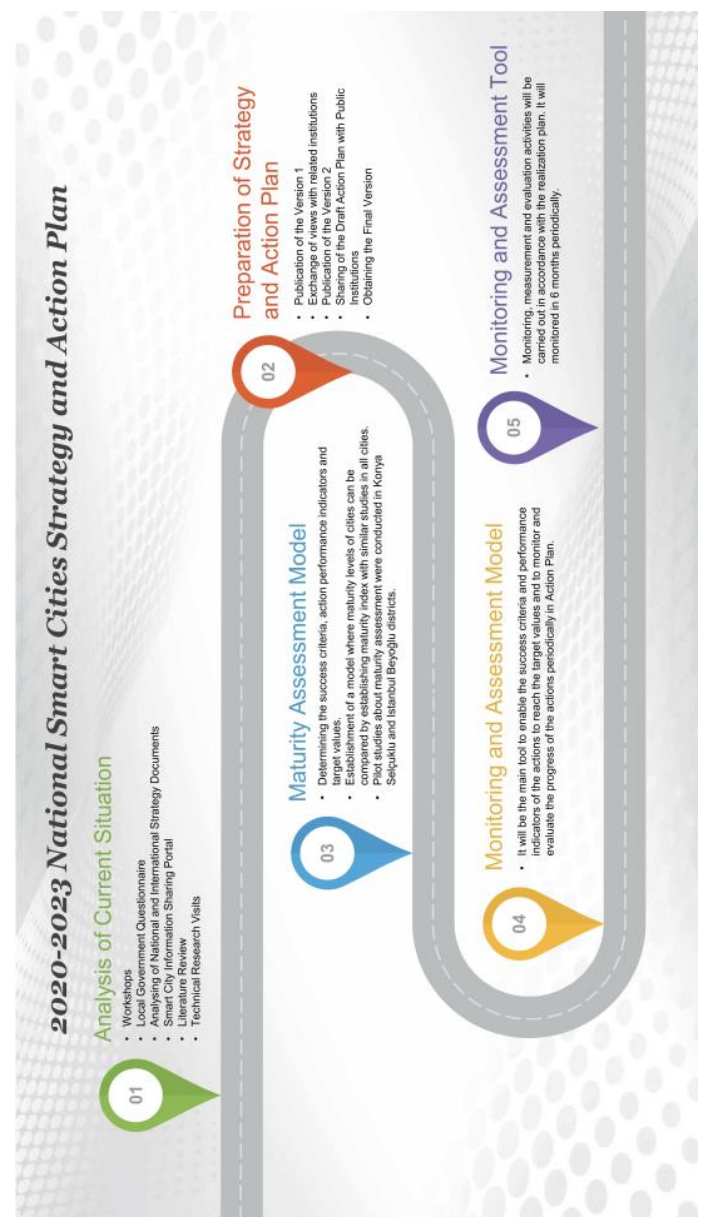

Figure 2. 2020-2023 National Smart Cities Strategy and Action Plan Road Map

Our priority actions are the establishment of a guidance mechanism that will guide local governments within the scope of smart city studies, and the realization of a smart city terminology and data dictionary that will provide common language use for smart city stakeholders. In addition, it is aimed to develop the world's one of the first Interoperability Model and Reference Architecture Model, which includes interoperability of smart city entities and relationships between 
these entities. On the other hand, the studies have been started for the establishment of a Smart City Technology Radar which includes to create an ecosystem in which efficient smart city technologies and applications are accredited. Thus, an environment where technologies proposed to be used will be encouraged and information security protection profiles will be developed. Within the scope of the project, by the implementation of Smart City Maturity Evaluation Model specific to Turkey, it is aimed to determine the competencies of cities in Turkey related to smart city governance and implementations by conducting interviews with all partners. With this model, it is targeted to increase the smart city awareness by measuring the maturity level of the cities and to improve this level where it is needed. The measurement method to be used within the scope of the Monitoring Evaluation Model will be the main tool that will enable the partners of the Smart Cities Ecosystem to monitor and evaluate the progress criteria of the Action Plan and the performance indicators of the actions. Smart Cities Information Sharing Portal (www.akillisehirler.gov.tr) is ready to be used to share information and experience among all smart city ecosystem stakeholders.

\section{CONCLUSIONS}

For the management of urban infrastructures and resources, it is inevitable to transform into smart cities for the purpose of providing the present and future needs of citizens efficiently. The goal of the National Smart Cities Strategy and Action Plan which is also included in The Action Plans of Presidency of The Republic of Turkey, 11th. Development Plan (2019-2023) and New Economic Program (2020-2022); is to invest in technology to improve environmental conditions while promoting economic growth and social development in cities.

2020-2023 National Smart Cities Strategy and Action Plan carried out at the national level is a guiding document for studies to be carried out in the field of smart cities and municipalities' strategies in our country. It can also be considered as a milestone for the smart city works to be carried out at the national and international level.

Turkey's 2020-2023 National Smart Cities Strategy and Action Plan has been completed and approved officially by the Presidency of Turkish Republic. According to Presidential Circular, all public institutions and organizations within the scope of the 2020-2023 National Smart Cities Strategy and Action Plan must fulfil their duties and responsibilities under the coordination of the Ministry of Environment and Urbanization.

\section{REFERENCES}

BSI, 2014. PAS 180: 2014 Smart cities - Vocabulary. The British Standards Institution, London, ENGLAND.

BIS, 2013. Smart Cities Background Paper. Department for Business, Innovation and Skills, London, ENGLAND.

Policy Department, Economic and Scientific Policy, Directorate-General for Internal Policies, 2014. Mapping Smart Cities in the EU. European Parliament (January 2014).

Cosgrove M and al, 2011. Smart Cities Series: Introducing the IBM City Operations and Management Solutions. IBM.
Manchester Digital Development Agency, 2019. What is a Smart City?. https://www.centreforcities.org/reader/smartcities/what-is-a-smart-city/ (29 May 2014).

City of Copenhagen Definition, 2019. https://www.smartcircle.org/smartcity/blog/definition-of-a-smart-city/ .

ITU, 2016. Shaping Smarter and More Sustainable Cities. ITUT's Technical Reports and Specifications, International Telecommunication Union, Geneva, SWITZERLAND.

General Directorate of Geographical Information Systems, 2019. 2020-2023 National Smart Cities Strategy and Action Plan, The Ministry of Environment and Urbanization of Turkey, Ankara, TURKEY.

BSI, 2014. PAS 181: Smart City Framework $\mathrm{k}$ - Guide to establishing strategies for smart cities and communities. The British Standards Institution, London, ENGLAND.

BSI, 2014. ISO 37120:2014 Sustainable development of communities - Indicators for city services and quality of life. The British Standards Institution, London, ENGLAND.

UNECE, 2015. The UNECE-ITU Smart Sustainable Cities Indicators. United Nations Economic Commission for Europe, Economic and Social Council, Geneva, SWITZERLAND (2 October 2015).

Centre of Regional Science, 2007. Smart cities - Ranking of European medium-sized cities Final Report. Centre of Regional Science, Vienna, AUSTRIA (October 2007). 